\title{
The effects of deposition parameters on CdS thin films optoelectronic properties
}

[Wagah F. Mohamad and Munther N. Al-Tikriti]

\begin{abstract}
Cadmium sulfide CdS has band gab of $2.42 \mathrm{eV}$, which is suitable as window material for thin film to fabricate solar cell. It has high absorption coefficient and acceptable conversion efficiency in addition to its low cost. Many samples are prepared using vacuum evaporation techniques with different deposition parameters. Hall Effect, resistivity and optoelectronic measurements are conducted on the fabricated samples. The analysis of the results indicates that the optoelectronic properties, namely photogenerated current are dependent on the thickness, substrate temperature and deposition rate.
\end{abstract}

Keywords - Cadmium sulfide thin films, optoelectronic. Hall effects, resistivity, photogenerated current, thermal deposition.

\section{Introduction}

Cadmium sulfide is positioned in the II-VI group [in the chemical elements periodic table]. It is commonly used in the fabrication of electronic devices such as solar cell $[1,2]$, photodetector [3] and numerous other optoelectronic devices [4]. Cadmium sulfide posses, on the whole, an intermediate band gap of $2.42 \mathrm{eV}$. This feature makes the material quite suitable to be used as windows in thin films solar cells. It also has acceptable conversion efficiency, adequate absorption coefficient in addition to its low cost. Thin films, in general, have been subjected to numerous theoretical [5] and practical [6] research works. But on the other hand, further research is required to fully understand and improve the materials properties.

The structure of cadmium sulfide thin films is polycrystalline. Generally, the individual crystalline has good quality but they are interlaced by a high number of grain boundaries. These boundaries form regions of increased disorder where charges are usually trapped. This consequently, develops potential barrier that restrict carrier transportation movement. The electrical conductivity is affected by this barrier. When the voltage drop across the bulk grain is very much smaller by comparison with the voltage drop in the barrier, the film resistivity is inversely proportional with the grain size [7].

It must be noted that the grain size is a function of many deposition parameters. These are mainly the film thickness, deposition rate and temperature of the substrate. I-V characteristic, carrier concentration, dark resistivity and optoelectronic properties are investigated as a function of deposition parameters. Furthermore, Hall Effect parameters, and photogenerated current are calculated with respect to the deposition parameters.

Wagah F.Mohamad ${ }^{1}$ and Munther N. Al-Tikriti

Faculty of Engineering,

Philadelphia University,

Amman, Jordan

\section{Fabrication Process:}

Vacuum thermal deposition technique is used to fabricate the cadmium sulfide film with different thicknesses and on glass substrate. The fabrication parameters which include temperature of the substrate, thickness of the films and the vacuum pressure are all set by the evaporation system. At the start, the clean glass substrate is positioned inside the chamber and when the pressure reaches $10^{-4}$ Torr the substrate is heated and maintained at $300^{\circ} \mathrm{C}$ for two hours in order to improve the film adherence and degassing. The substrate is then cooled and kept at the required constant temperature during the deposition process. Then, aluminum Ohmic contacts are placed on top and bottom of each sample. The top aluminum contact is deposited through a mask so as to facilitate the photoelectronic measurement. The annealing process is performed by heating the samples in the chamber under vacuum.

In order to produce good films characteristics, the deposition rate plays an important role in the thermal evaporation technique. In this research work, a deposition rate of $2^{\circ} \mathrm{A} / \mathrm{sec}$ is used for all fabricated samples if not stated otherwise. With this rate of deposition the samples should have good adhesion and thermal stability. The annealing temperature is kept constant in this research work at $300^{\circ} \mathrm{C}$ and its effect will be investigated in future research work.

\section{Hall Effect Measurements:}

Equation (1) expresses the Hall constant $\mathbf{R}_{\mathbf{H}}$ as a function of the carrier concentration (n) [8]

$$
\mathbf{R}_{\mathbf{H}}=\mathbf{r} /(\mathbf{n e})
$$

$\mathbf{r}$ the scattering factor which is between 1 and 2 but more closer to one, $\mathbf{e}$ is the electronic charge. Thus:

$$
\mu_{H}=\mathbf{R}_{H} \sigma=\mathbf{R}_{H} / \rho_{B}
$$

$\boldsymbol{\mu}_{\mathbf{H}}$ is the Hall mobility while $\boldsymbol{\sigma}$ represents the film conductivity and $\rho_{\mathrm{B}}$ the bulk resistivity.

$$
\rho_{B}=r /\left(n \text { e } \mu_{H}\right)
$$

The grain size must be increased in order to reduce the resistivity of the sample. It can be stated that the carriers concentration is directly proportional to the processing parameters, which include, the substrate temperature, film thickness and annealing temperature [9, 10]. The Hall measurement indicated that all the fabricated films are $n$ type i.e. negative Hall coefficient [11]. In this case the electrons are the majority charge carriers. Figure (1) shows the variation of the average carries concentration (n) and Hall mobility with the thickness of the films at substrate 
Proc. of the Seventh International Conference On Advances in Computing, Electronics and Electrical Technology - CEET 2017. Copyright (C) Institute of Research Engineers and Doctors. All rights reserved.

ISBN: 978-1-63248-126-9 doi: 10.15224/ 978-1-63248-126-9-27

temperature $180^{\circ} \mathrm{C}$. It is clear from the figure that, the carrier concentration increases sharply as a function of the film thickness in the region when the thickness is less than 1.2 $\mu \mathrm{m}$ but it decreases sharply when the film is thicker. This is due to the fact that at thicker films become rich with cadmium (donor level), which increases the carrier concentration during the deposition process.

Figure 1 also, shows the variation of the mobility with the thickness of the film. It can be clearly noted that the mobility varies markedly with the thickness. The significant change in the mobility occurs in conjunction with the change in grain size. However, when the surface carrier concentration is increased, the potential barrier tends to reduce the number of carriers that reach the surface. In other word, this indicates that the mobility is limited by the intergrain barriers. Consequently, if the carrier concentration is increased beyond certain limits the resistivity will tend to increase causing the Hall mobility to decrease [12].

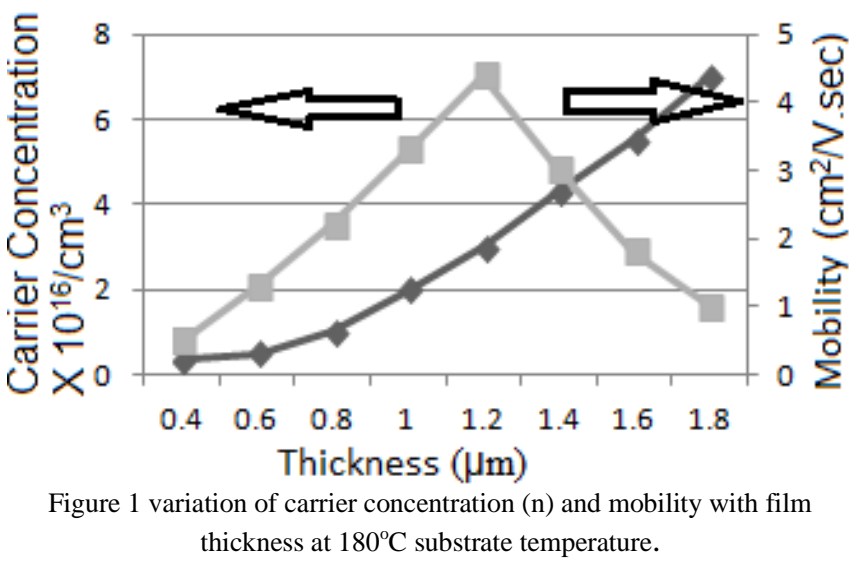

Figure 2 shows the variation of Hall mobility and carrier concentration with substrate temperature for two samples of $1.2 \mu \mathrm{m}$ thickness. Sample 1 is not heat treaded, while the other sample 2 is heat treated in vacuum at $300^{\circ} \mathrm{C}$ for 30 minutes. In the untreated films the carrier concentration will increase with the increase of the substrates temperature and reaches a maximum value at substrate temperature of $180^{\circ} \mathrm{C}$.

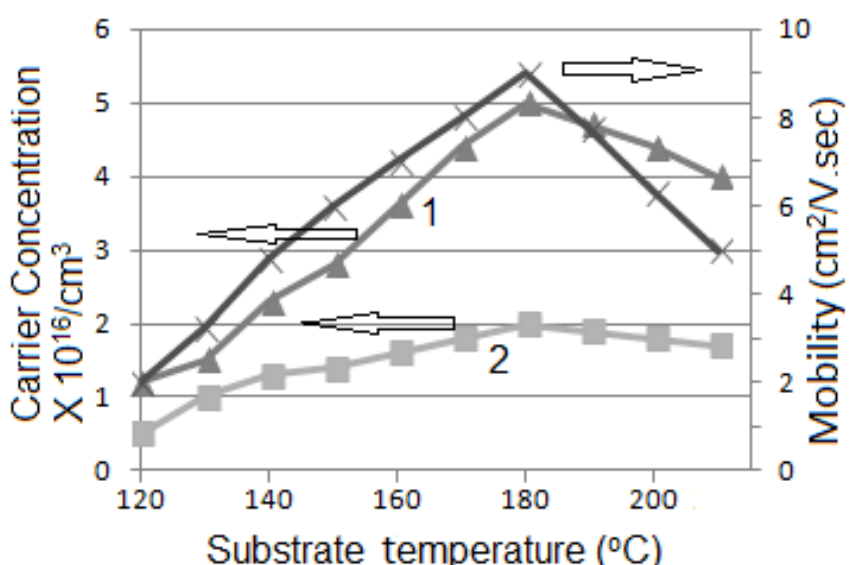

Figure 2 shows the variation of Hall mobility and carries concentration with substrate temperature for sample with $1.2 \mu \mathrm{m}$ thickness.

The heat treated film shows lower values of carrier concentration. This is due to the fact that the films have become rich with sulfur atoms (accepter level) which results in higher resistivity and small grain size. The Hall mobility behaves in similar manner as the carrier concentration which means that both of them are dependent on the grain size. It follows, when the temperature of the substrate is increased up to $180^{\circ} \mathrm{C}$, the degree of preferential orientation of the microcrystalline and the gain size will increase too. But their values will decrease when the temperature increases beyond $180^{\circ} \mathrm{C}$ due to the staking faults in the films. These results are in good agreement with previous published research work [13].

\section{Resistivity measurements:}

Figure 3 shows the variation of dark bulk resistivity with film thickness for $180^{\circ} \mathrm{C}$ substrate temperature. It can be seen that the film resistivity decreases sharply as the thickness increase up to $1.2 \mu \mathrm{m}$ beyond this thickness the decline in the resistivity become less pronounced where the films are thicker. This reduction in the resistivity is attributed to increase in carrier concentration and vertical growth of the film, which increases the crystalline size [14].

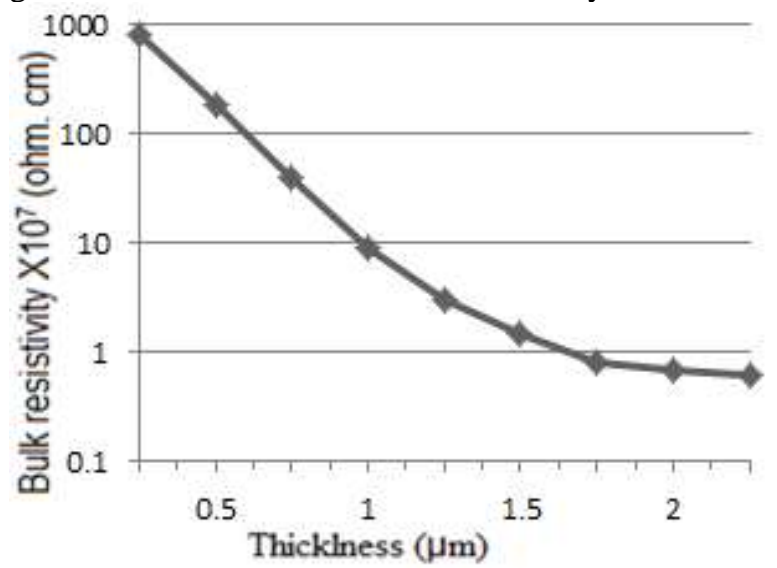

Figure 3 variation of dark bulk resistivity with film thickness for $180^{\circ} \mathrm{C}$ substrate temperature.

Figure 4 shows the surface and bulk resistivity as function of substrate temperature. The thickness is $1.2 \mu \mathrm{m}$ with deposition rate of $3^{\circ} \mathrm{A} / \mathrm{sec}$. All measurement are carried out inside a black box at room temperature. The figure shows that bulk and surface resistivity each decreases as the temperature increases, but it starts to increase when the substrate temperature increases beyond $180^{\circ} \mathrm{C}$.

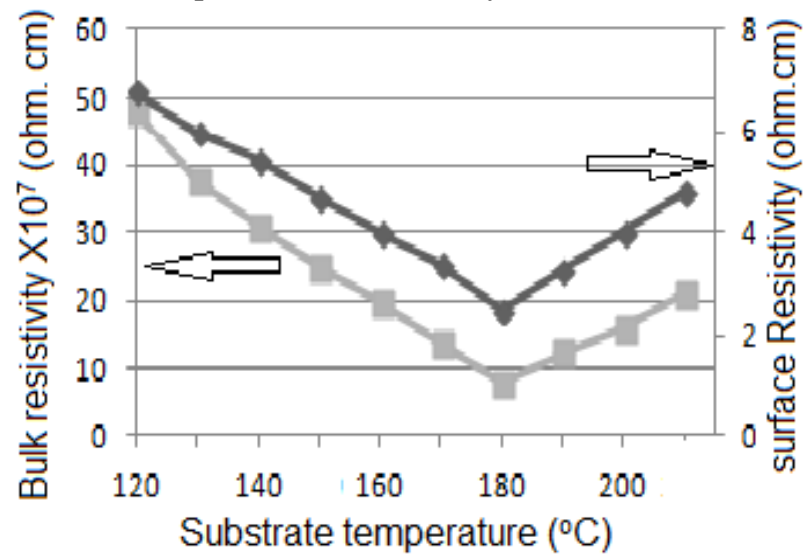

Figure 4 Variation of bulk and surface resistivity with substrate temperature for thickness $1.2 \mu \mathrm{m}$.

The resistivity's increase is due to two reasons. The first is the degree of preferential orientation of the microcrystallines 
Proc. of the Seventh International Conference On Advances in Computing, Electronics and Electrical Technology - CEET 2017. Copyright (C) Institute of Research Engineers and Doctors. All rights reserved.

ISBN: 978-1-63248-126-9 doi: 10.15224/ 978-1-63248-126-9-27

becomes less. The second reason is that at higher substrate temperature the adhesion coefficient of cadmium atoms is small hence the film becomes rich with sulfur. At high substrate temperature a number of the cadmium evaporated atoms rebounce (re- evaporate) from the substrate.

The surface current-voltage (I-V) characteristic for the fabricated films are measured and studied in the dark and at room temperature. Figure 5 shows the variation of the current with thickness for different biasing voltages. The current is directly proportional with thickness. It increases up to the point of the thickness $1.2 \mu \mathrm{m}$ but it starts to level of beyond this point due to resistivity increase as explained before.

The Ohmic contact between the cadmium sulfide and the aluminum is investigated. The conditions to obtain an Ohmic contact are:

$\varnothing_{\mathrm{ms}}<0, \varnothing_{\mathrm{Al}}=4.2 \mathrm{eV}, \varnothing_{\mathrm{cds}}(\mathrm{n})$ between. 4.63 and $4.93 \mathrm{eV}$

Hence $\emptyset_{\mathrm{ms}}=\varnothing_{\mathrm{A} 1}-\emptyset_{\mathrm{cds}}=-0.43$ to $-0.73 \mathrm{ev}$ which is negative.

$\varnothing_{\mathrm{ms}}, \varnothing_{\mathrm{A} 1}$ and $\varnothing_{\mathrm{cds}}$ are the metal-semiconductor, aluminum and CdS n-type work functions respectively. The polarity of the applied voltage has no effect on the I-V characteristics of the film which means that the contacts are Ohmic.

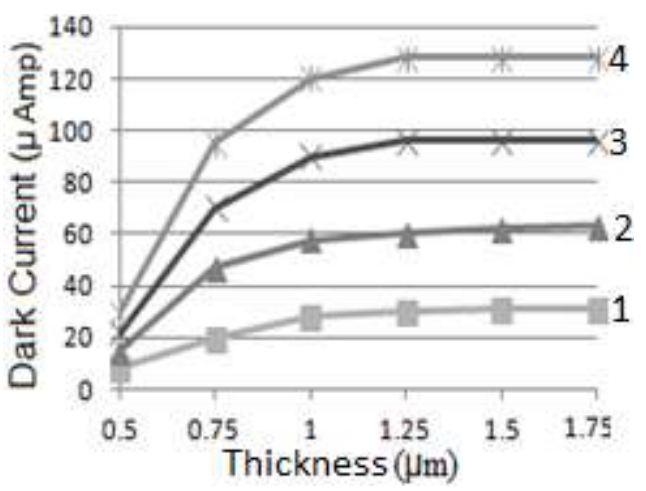

Figure 5 variation of current against thickness for different biasing voltage at substrate temperature $180^{\circ} \mathrm{C} .(1-\mathrm{V}=2 \mathrm{~V}, 2-\mathrm{V}=4 \mathrm{~V}, 3-\mathrm{V}=6 \mathrm{~V}, 4-\mathrm{V}=8 \mathrm{~V})$

\section{Photoelectronic Measurements:}

The photogenerated current behavior is studied with respect to the deposition parameters mainly the thickness of the film and substrate temperature.

In order to avoid excessive heating, the samples are exposed to light for $15 \mathrm{sec}$. during the measurement while the biasing voltage is kept at 2 volts. Figure 6 shows the variation of the photogenerated current with light intensities $(\varnothing)$ at $150^{\circ} \mathrm{C}$ substrate temperature for different thicknesses.

It is observed that the photogenerated current increases as the light intensity increased up to $\left(3.5 \mathrm{~W} / \mathrm{cm}^{2}\right)$ where beyond this light intensity the current reaches saturation. This can be explained due to the effect of series resistance which increases with light intensity [15]. This effect will limit the advantage of the use of high light intensity. It can be also note that the photogenerated current increases with thickness and up to $1.2 \mu \mathrm{m}$ and then the difference in the photogenerated current between the plots tends to become smaller with increase in thickness. This is because of the formation of dead layer at high film thickness.

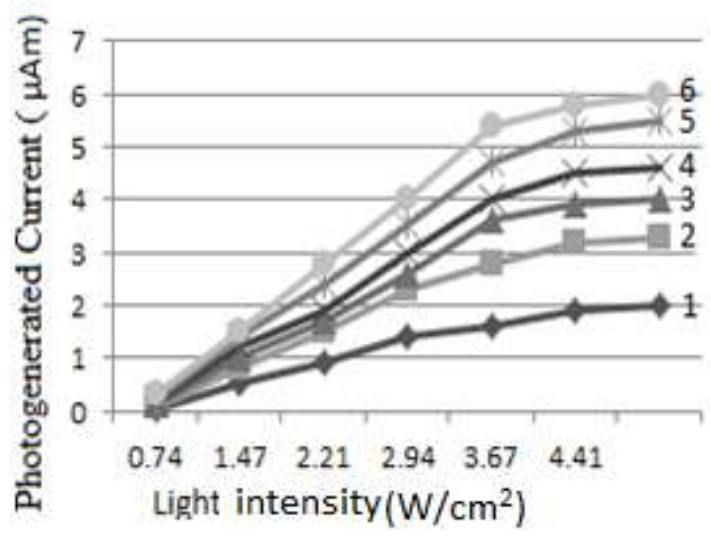

Figure 6 variation of photogenerated current with light intensities for $180^{\circ} \mathrm{C}$ substrate temperature at different thicknesses $(1-0.6 \mu \mathrm{m}, 2-0.8 \mu \mathrm{m}, 3-1 \mu \mathrm{m}$, 4- $1.2 \mu \mathrm{m}, 5-1.4 \mu \mathrm{m}, 6-1.6 \mu \mathrm{m})$.

Figure 7 represents the variation of the photogenerated current for different light intensities at different substrate temperatures. It is evident, that the relation is almost linear with substrate temperature. The current exhibits maxima at $180^{\circ} \mathrm{C}$ this due to the fact that the atoms start to rebounce from the substrate at temperature higher than $180^{\circ} \mathrm{C}$. Beyond this point the increase in photogenerated current becomes small as it can be seen plot 4 almost coincides with plot 3 .

This is attributed to increase in cadmium sulfide conductivity and the breakage of the bands inside the substrate increases the electron-hole pair generation as the photons flux increases [16].

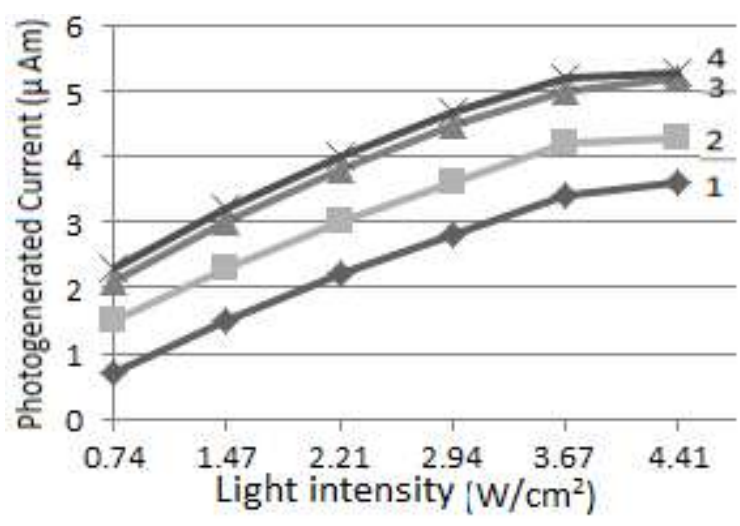

Figure 7 Variation of photogenerated current with light intensity $(\varnothing)$ at $1.2 \mu \mathrm{m}$ film thickness at different substrate temperatures $\left(1-120^{\circ} \mathrm{C}, 2\right.$ $150^{\circ} \mathrm{C}, 3-180^{\circ} \mathrm{C}, 4-210^{\circ} \mathrm{C}$ ).

In order to confirm that low rate of deposition produces films with good characteristic. The dependence of the photogenerated current on deposition rate is given figure 8 . The photogenerated current is inversely proportional with the deposition rate with strong dependency at low rates. This is because of the atoms arrangement at low rate and the generation of bigger gain size. 


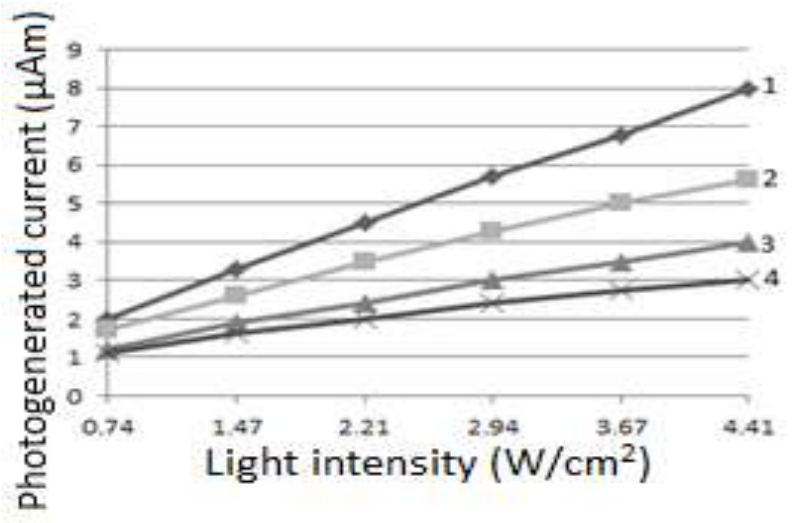

Figure 8 variation of photogenerated current with light intensities at $1.2 \mu \mathrm{m}$ thickness $180^{\circ} \mathrm{C}$ at different substrate temperatures (1- $0.2 \mathrm{~A} / \mathrm{sec}, 2-0.4$ $\mathrm{A} \% \mathrm{sec}, 3-0.6 \mathrm{~A} / \mathrm{sec}, 4-0.8 \mathrm{~A} \% \mathrm{sec})$

\section{v. Conclusions}

The study and analysis of the results indicates the following conclusions:

\section{A. Hall effect measurements:}

The carrier concentration increases sharply with the increase of thickness but it decreases sharply after $1.2 \mu \mathrm{m}$ thickness. The Hall mobility, on the other hand, varies with the thickness and is limited by the intergrain barrier. However the Hall mobility tends to decrease with increase of resistivity which is affected by any increase in carrier concentration. Also the carrier concentration and Hall mobility increase with substrate temperature and maximize at $180^{\circ} \mathrm{C}$ and both parameters are dependent on grain size.

\section{B. Resistivity measurements:}

The resistivity decreases sharply with thickness but the decrease becomes less steep beyond $1.2 \mu \mathrm{m}$ thickness due to increase in carrier concentration. The resistivity decreases when the substrate temperature increases up to $180^{\circ} \mathrm{C}$ but beyond that it increases. $\mathrm{I}-\mathrm{V}$ characteristic shows that the current is directly proportional with voltage and it increases for thickness up to $1.2 \mu \mathrm{m}$, where after that it starts to saturate due to increase in resistivity. The results indicate that the aluminum contact is Ohmic.

\section{Photoelectronic measurements:}

The photogenerated current increases with light intensity but reaches saturation due series resistance. The photogenerated current also increases with thickness and saturate beyond $1.2 \mu \mathrm{m}$, the current also increases with temperature of substrate and maximizes at $180^{\circ} \mathrm{C}$. Also the current is inversely proportional with the deposit rate and it best with low deposition rate.

\section{Acknowledgment}

The authors are very grateful to Philadelphia UniversityAmman-Jordan for providing all required facilities to conduct this research and for their support and encouragement. Grateful thanks to Miss Shatha Al-Awatli for typing the manuscript

\section{References}

[1] W. F. Mohamad and A. S. Dawood, "Improved efficiency of $\mathrm{Cu}_{2} \mathrm{~S}-\mathrm{CdS}$ solar cell" JIETE journal, India, Vol. 33(1), PP. 70-71, (1987).

[2] CH. Ashok, K. V. Rao, CH. S. Chakra, K. G. Rao" Structural and Optical Properties of CdS Thin films for the Solar Cell Applications" International Journal of Science and Research (IJSR), Vol. (), PP. 26-27, (2013):

[3] K. Deng and L. Li" CdS nanoscale photodetectors" Advance materials, Vol. 26(17) PP. 2619-2635, (2014).

[4] I. Rathinamala, J. Pandiarajan, N. Jeyakumaran and N. Prithivikumaran., 'Investigations on structural and optical properties of $\mathrm{CdS}$ films fabricated by spin coating technique for optoelectronic applications" International Journal of Chem.Tech. Research,Vol. 6, No.3, pp. 1913-1915, ( 2014).

[5] M.A. Mahdi, S.J. Kasem, J.J. Hassen and S. K. J. Ani "Structural and optical properties of chemical deposition CdS thin Films," International Journal of Nanoelectronics and Materials, Vol.2, pp.163-172, (2009).

[6] W. F. Mohamad and A. M. Nory," The photoelectric and thermal properties of vacuum deposited CdS thin films," Renewable Energy, Vol. 14(1-4), PP. 129-134, (1998).

[7] Y. H. Sun, Y. J. Ge, W. W. Li, F. Huang, Chen, L. Y. Shang, P. X. Yang and J. H Chu, "Structural and optical analysis of $\mathrm{CdS}$ thin films grown by magnetron sputtering technique," Journal of Physics, Vol. 276(1), pp. 1190-1195, (2011).

[8]M. S. Banet, "Relationships between Hall constant and carrier densities in polycrystalline semiconductor films", J. Appl. Phys, Vol. 58(9), PP. 3470-3475, (1985).

[9] A. Ashour, N. El-Kady and S. A. Mahmoud" On the electrical and optical properties of CdS films thermally deposited by modified source" 1 st int. spring school and symposium on advanced and advanced materials science (SAMS 94), PP. 1144- 1150, (1994).

[10] Z Aneva, D Nesheva, C Main, S Reynolds, A G Fitzgerald and E Vateva" Electrical properties of nanocrystalline $\mathrm{CdSe}$ thin films prepared by thermal vacuum evaporation" Semiconductor Science and Technology, Volume 23, Number 9, (2008).

[11] "Standard test methods for measuring resistivity and Hall coefficient and determining Hall mobility in Single Crystal Semiconductors," ASTM Designation F76, Annual Book of ASTM Standards, Vol. 10.05 (2000).

[12] E. Berton, J. L. Morentza J. Esteve" Dependence of transport parameters on thickness in doped polycrystalline thin films" J. Appl. Phys. Vol. 56 (6), PP. 1738- 1743, (1984) .

[13] L. L. Kazmerski, W. B. Berry and C. W. Allen” Role of CdS thin film II staking faults" J. app. Phys. Vol. 43(8), PP. 3521- 3527, (1972).

[14] J. Dutta, D. Bhattacharyya, S. Chaudhuri, A.K. Pal "Photoconductivity in polycrystalline semiconductors: Grain boundary effects" Solar Energy Materials and Solar Cells, Vol. 36 (4), PP. 357-368, (1995).

[15] W. F. Mohamad and M.Shehatha," The effect of series resistance on photovoltaic properties of In-doped CdTe (p) 
Proc. of the Seventh International Conference On Advances in Computing, Electronics and Electrical Technology - CEET 2017. Copyright (C) Institute of Research Engineers and Doctors. All rights reserved.

thin film homojunction", Renewable Energy J., England, Vol. 21(2), P. 141, (2000).

[16] J. W. Orton and M. J. powell" The Hall effect in polycrystalline and powered semiconductors" Reb. Prog. Phys., Vol.43, PP. 1264-1305, (1980).
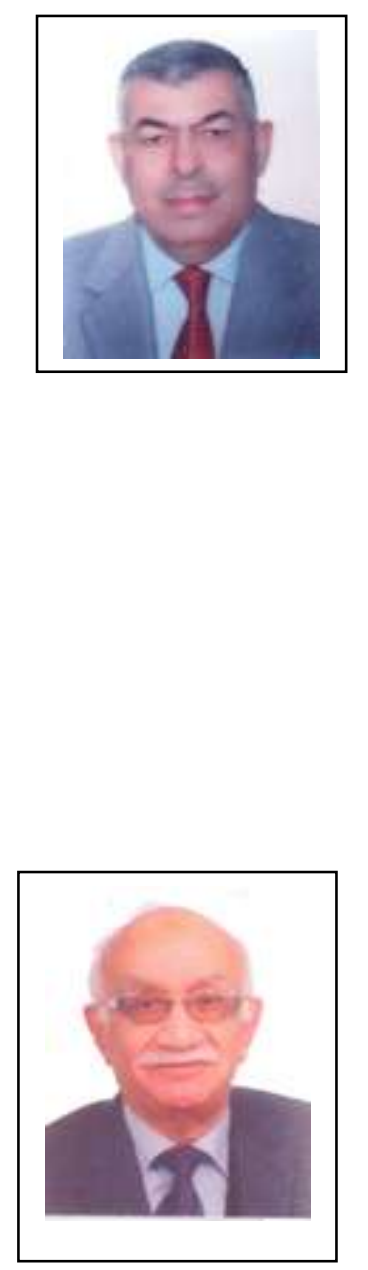

Dr. Wagah F. Mohammad is professor of electronic and head of electronic research group in Philadelphia University, Jordan. He was awarded his Master degree and $\mathrm{PhD}$ in Electronics and Electrical Engineering from Manchester University, England; 1977 and 1980 respectively. He teaches courses on analogue Electronics, digital electronics, microelectronics, solid state electronics and advanced design of digital electronics. His research interests includes design and fabrications of microelectronics circuits, fabrication and characterization of thin films, photodetectors fabrications, applications and fabrication also investigation solar cells. $\mathrm{He}$ published two scientific books and more than fifty papers in reviewed journal and international conferences. He supervised five $\mathrm{PhD}$ students and more than 15 M.Sc. students. $\mathrm{He}$ has long experience with academic administration as a head of research group, head of department, deputy dean and dean of engineering college.

Dr. Munther N. Al-Tikriti is professor of control engineering and head of scientific research at the faculty of engineering, Philadelphia University. He has B.Sc.(Hon) in electrical engineering from London University 1967and M.Sc. \& Ph.D. in control engineering from Salford University England. Research interest are in control engineering , measurement and electronics 